\begin{tabular}{|l|l|l||}
\hline \multicolumn{2}{|c|}{ PublisherInfo } \\
\hline \hline PublisherName & $:$ & BioMed Central \\
\hline \hline PublisherLocation & $:$ & London \\
\hline \hline PublisherImprintName & $:$ & BioMed Central \\
\hline \hline
\end{tabular}

\title{
Long-term weight loss lowers BP in mildly hypertensive overweight patients
}

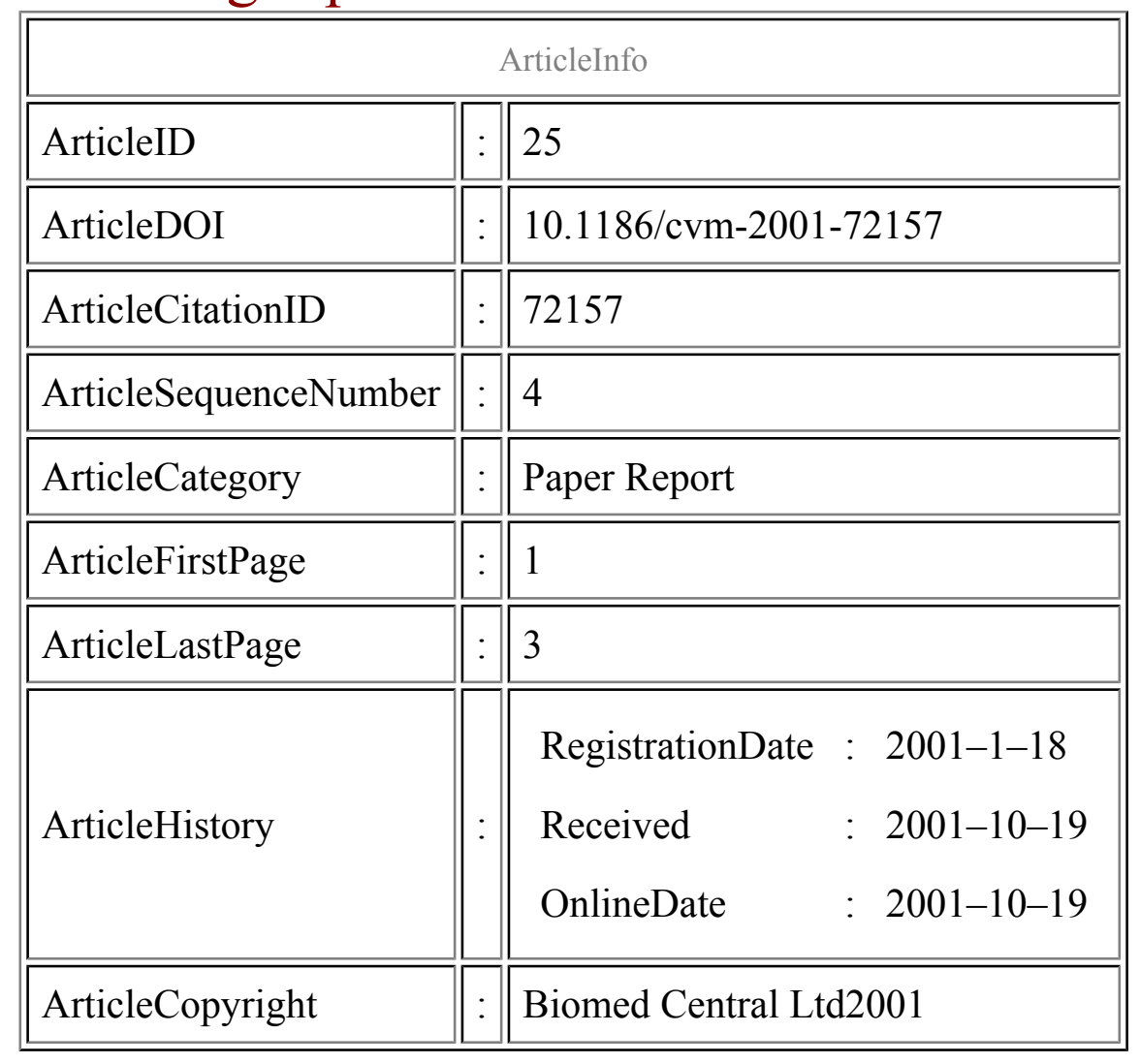




\begin{tabular}{|l|l|l|}
\hline ArticleGrants & $:$ & \\
\hline \hline ArticleContext & $:$ & 1306322 \\
\hline
\end{tabular}

Joanna Lyford, ${ }^{\text {Aff1 }}$

Corresponding Affiliation: Aff1

Aff1 MedWire, U.K

Keywords

Blood pressure, diet therapy, exercise, hypertension, weight loss

\section{Context}

Sustained weight loss resulting from lifestyle interventions can achieve clinically significant reductions in blood pressure, a randomized clinical trial confirms.

\section{Significant findings}

Lead investigator Victor Stevens and colleagues report that at 6, 18, and 36 months, participants in the weight loss program had lost an average of 4.4, 2.0 , and $0.2 \mathrm{~kg}$, respectively, whereas participants in the usual care group had gained $0.1,0.7$, and $1.8 \mathrm{~kg}$. Although not all participants assigned to the weight loss group lost weight, those who did showed favorable decreases in blood pressure. The risk ratio for hypertension in the intervention group was 0.58 (95\% CI 0.36-0.94) at 6 months, $0.78(0.62-1.00)$ at 18 months, and $0.81(0.70-0.95)$ at 36 months. In subgroup analyses, intervention participants who lost at least $4.5 \mathrm{~kg}$ at 6 months and maintained this weight reduction for the next 30 months had the greatest reduction in blood pressure and a relative risk for hypertension of $0.35(0.20-0.59)$.

\section{Comments}

The investigators admit that since over three-quarters of the study participants were white, more than two-thirds were men, and half were college graduates, it is uncertain whether these results apply to 
persons with other characteristics. However, they believe that their data support that concept that in overweight patients with slightly elevated blood pressure, 'even modest weight loss can result in clinically significant reductions in blood pressure' and also reduce the risk of developing hypertension.

\section{Methods}

Data from the weight loss arm of the Trials of Hypertension Prevention (TOHP) II were analyzed to investigate the long-term effects of weight loss on blood pressure. TOHP II included 1191 adults aged $30-54$ years who were between $10 \%$ and $65 \%$ above their ideal body weight and had nonmedicated high-normal blood pressure at baseline. Participants assigned to weight loss intervention $(n=595)$ were compared with usual care controls $(n=596)$. The weight loss program involved three years of regular group meetings, and individual counseling that focused on diet, physical activity, and social support.

\section{Additional information}

\section{References}

1. Stevens VJ, Obarzanek E, Cook NR, Lee IM, Appel LJ, Smith West D, Milas NC, Mattfeldt-Beman M, Belden L, Bragg C, Millstone M, Raczynski J, Brewer A, Singh B, Cohen J, for the Trials of Hypertension Prevention Research Group : Long-term weight loss and changes in blood pressure: results of the Trials of Hypertension Prevention, Phase II. Ann Intern Med. 2001, 134: 1-11.

This PDF file was created after publication. 